\title{
O JARDIM NA CIDADE É UM FRAGMENTO DE SONHO
}

\section{THE GARDEN IN THE CITY IS A DREAM'S FRAGMENT}

Miranda Martinelli Magnoli

Professora titular da Faculdade de Arquitetura e Urbanismo da Universidade de São Paulo (FAUUSP). E-mail:mmemm@uol.com.br

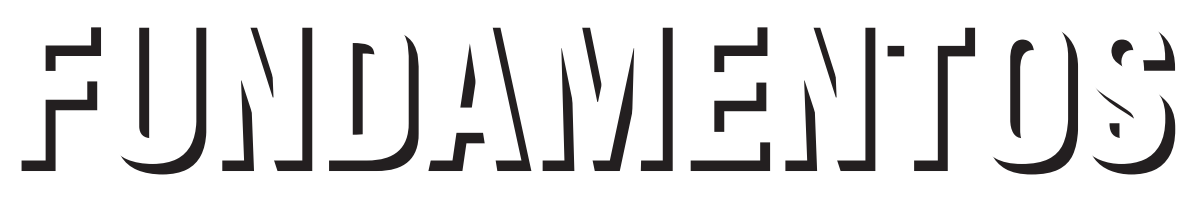




\section{RESUMO}

O texto abre um leque de questões, buscando traçar objetivos de pesquisa, estudos e ação para o arquiteto que trata com a paisagem e, em especial, com os espaços livres urbanos, mostrando o quanto é grande a responsabilidade do paisagista no Brasil, perante seus conflitos sociais e ambientais. $O$ título não passa de uma metáfora provocativa para um início de discussão mais profundo a que se propõe.

Palavras-chave: Jardim, meio ambiente, globalização, espaços livres, paisagem, área verde.

\section{ABSTRACT}

This paper is the result of a conference developed by Miranda Magnoli in 1996 at $2^{\text {nd }}$ ENEPEA (Encontro Nacional de Ensino de Paisagismo em Escolas de Arquitetura e Urbanismo no Brasil) in FAUUSP. She focused the main questions and subjects for the Brazilian national landscape studies to be developed in this time. The idea that the garden in a city is a dream's fragment is the start to dozens of other important questions.

Key words: Garden, environment globalization, open spaces, landscape, green space. 


\title{
O JARDIM NA CIDADE É UM FRAGMENTO DE SONHO
}

\author{
THE GARDEN IN THE CITY IS A DREAM'S FRAGMENT
}

\section{Introdução}

A cidade densamente construída é o lugar por excelência do espaço livre público contemporâneo. É a esse espaço que cabe o papel de requalificar a cidade existente.

E que caráter terá esse espaço? Com que abordagem enfrentar o projeto desse espaço? Com quais insumos propor o desenho desse espaço?

É uma concepção já clara em países que já não querem aceitar a violência de milhões vivendo na pior miséria, em cidades mais conscientes dos benefícios decorrentes de um país mais justo, de um país com divisões tênues, de segregações menos indignas. É uma concepção válida também para um país que não é pobre, nada pobre, mas terrivelmente injusto. Em momento algum estou pretendendo que o espaço seja a resposta para um país justo.

Esta "concepção meta" não abre mão dos conteúdos necessários na formação do arquiteto; não abre mão, muito pelo contrário, dos campos de pesquisa a serem abertos ou aperfeiçoados. Não abre mão dos conceitos formulados nos estudos das últimas décadas, nem pretende substituí-los ou reformulá-los; somente novos estudos poderiam indicar-nos a substituição ou reformulação.

Também não abre mão das possibilidades de ver a cidade como um ambiente em que as características físicas podem ser melhoradas com a introdução do material entendido como natural - preponderantemente a vegetação. Porém, privilegia, coloca atenção mais intensa sobre a mensagem cultural trazida por um qualquer espaço, quando este é realizado dentro do contexto da cidade, do ambiente tecido pela cidade.

Esse não é um conflito de posições. Por uma delas, em geral denominada ecológica, preconiza-se a transformação do ambiente urbano por meio da introdução do material natural. Pela outra se entende que não cabe ao espaço livre, ao "jardim" urbano (verde ou não), assumir as responsabilidades da deterioração progressiva de todos os aspectos vitais do ambiente humano (atmosfera, águas, biodiversidade, etc.). De qualquer forma, os desenhos, os projetos não deixariam de levar em conta, em sua organização, a ecologia, já parte da cultura de nosso tempo.

Faço minhas as palavras do paisagista francês Michel Corajoud, quando afirma: "o século $X I X$, ao acentuar tão intensamente o viés higienista, prestou um mau serviço aos jardins"; diz ele: "o jardim não é feito para compensar as lacunas da cidade, nem para, simplesmente por ele, introduzir a natureza na cidade. O jardim na cidade é um fragmento de sonho, e não um enclave necessário para trazer ar para o cidadão". 


\section{Os Jardins Como Fragmentos de Sonho}

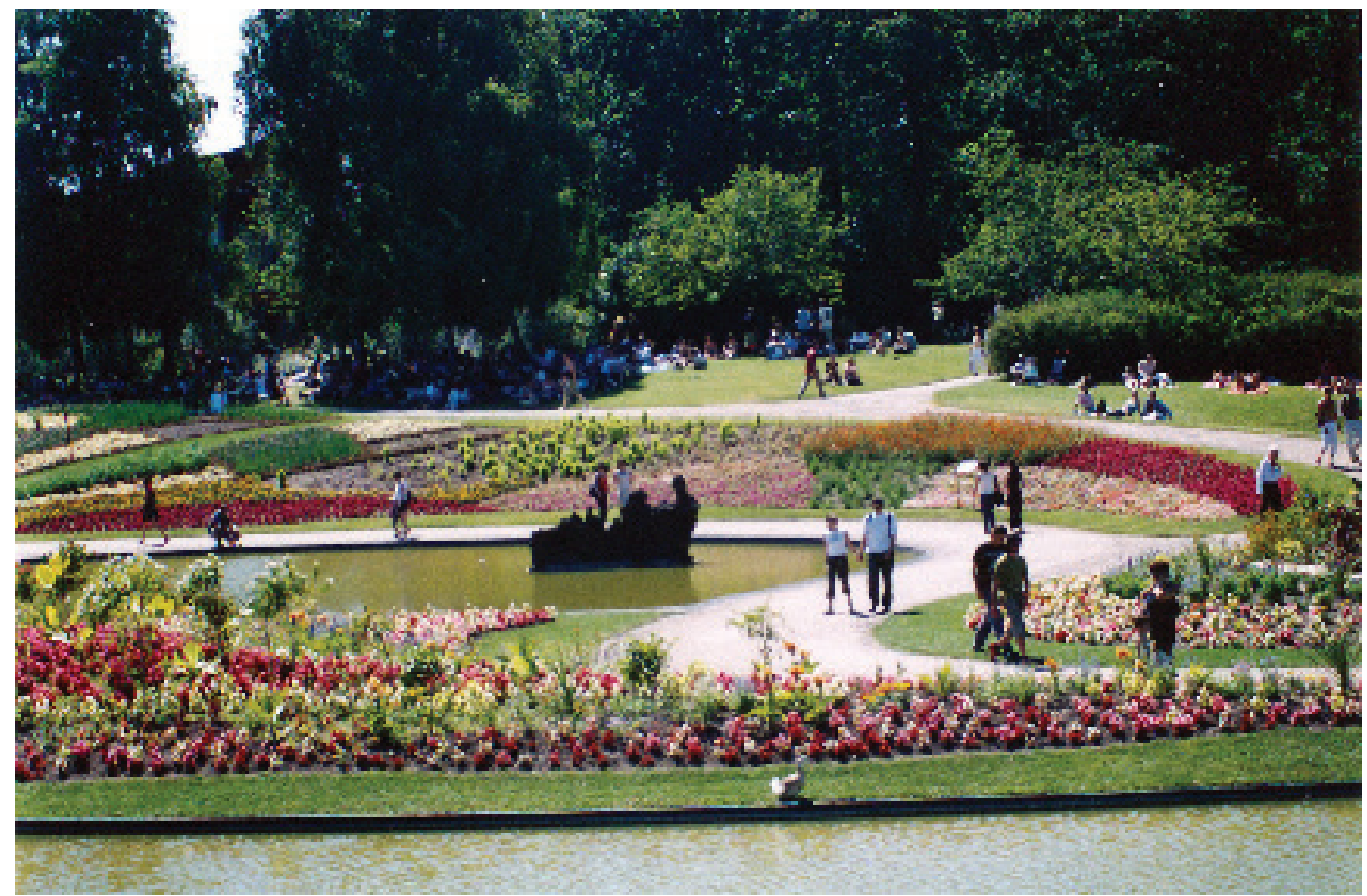

Foto 1: Jardins florais, Bois de Vincennes

Crédito: Silvio Macedo, 2004

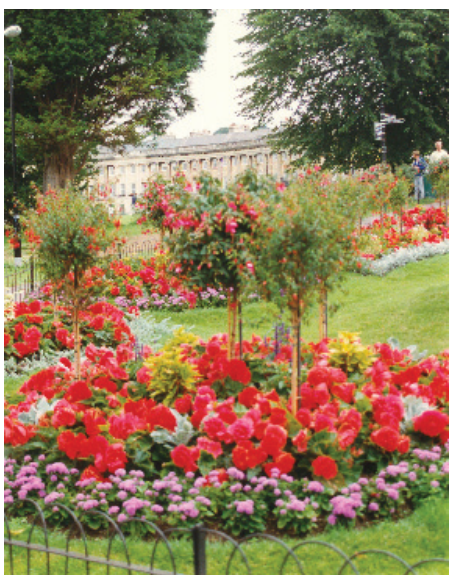

Foto 2: Jardins urbanos Bath, Inglaterra

Crédito: Silvio Macedo, 1997

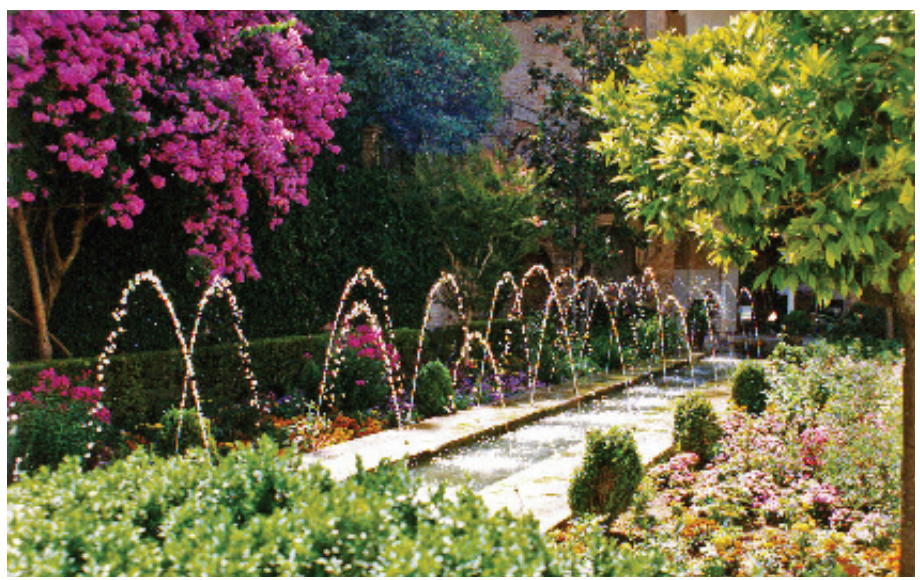

Foto 3: Jardins Genernife Alhambra,

Granada, Espanha

Crédito: Silvio Macedo, 1997

Também já não nos basta a compreensão da importância do espaço físico no modo de estabelecerem-se as relações sociais; já avançamos na observação, na análise, de espaços nos quais, ao invés do "fragmento de sonho", de Corajoud, a organização dos espaços leva aos habitantes um cotidiano condicionador da reprodução de comportamentos tais, que se reafirma a estrutura da formação social urbana existente. 

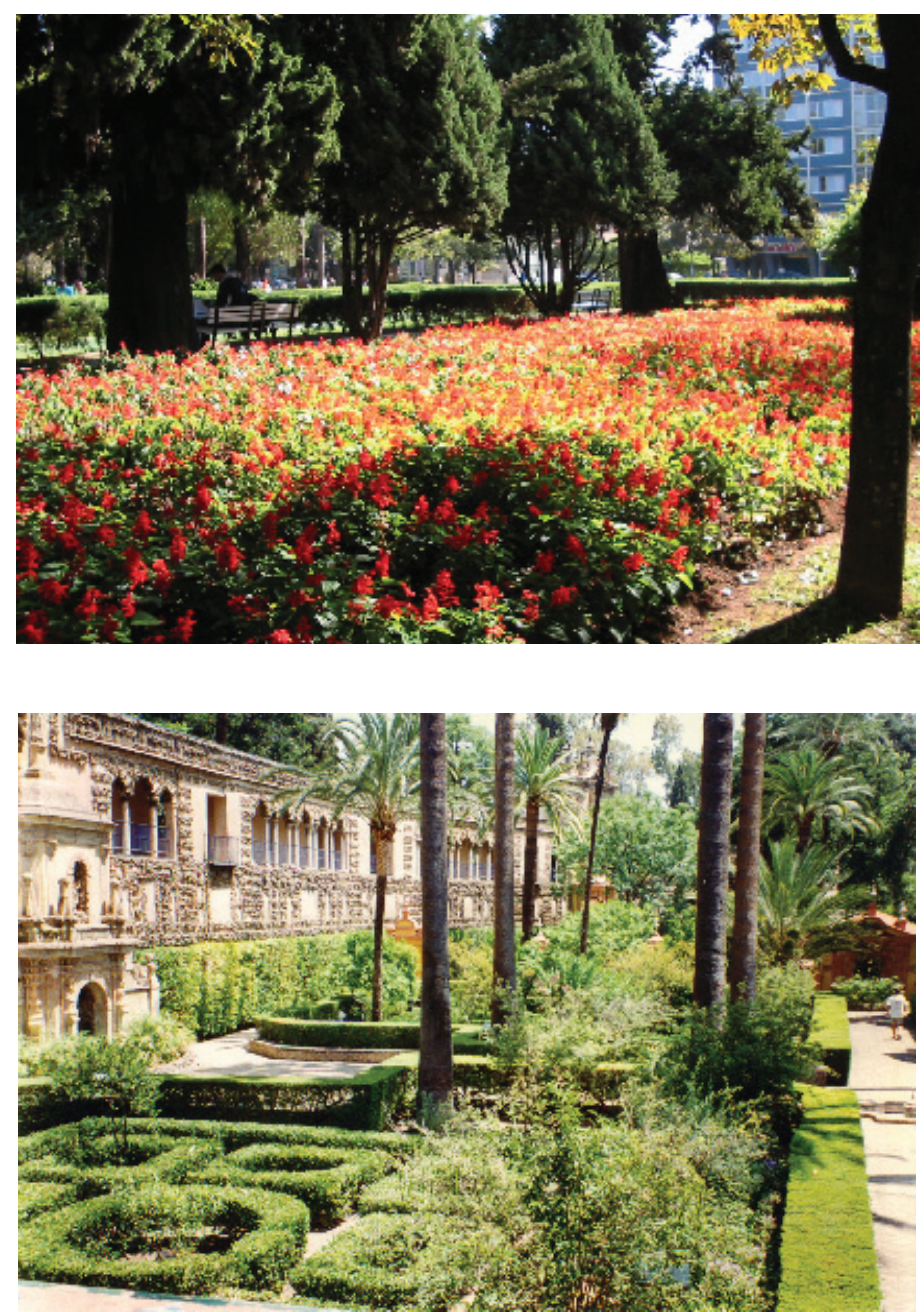

Foto 4: Praça da Liberdade, Belo Horizonte, MG, Brasil

Crédito: Fabio Robba, 2004

Foto 5: Jardins Alcaçar, de Sevilha Crédito: Silvio Macedo, 1997

Conseguimos, a duras penas, dar início ao processo de compreensão das questões regionais. Porém, ao se colocar como meta de atuação, os espaços internos ao tecido social das cidades não se baseiam simplesmente na urbanização crescente da população brasileira $(88 \%$ no Sudeste do país); não se confunde meta de atuação com o necessário, e indispensável processo de compreensão da produção da paisagem a partir de uma escala maior, incorporando a questão regional, para ação em um lugar específico, em um certo tecido social de uma cidade de uma região.

Processo de projeto é meta do arquiteto. Escala de atuação não se confunde com escala de compreensão. Essa escala de atuação e esse processo, aparentemente tão simples, exigem enfrentamentos, desafios, entendimentos, para os quais estamos muito longe de estar preparados.

Ao nos exigirmos uma abordagem simultaneamente geral e particular, vem à tona, de pronto, a heterogeneidade: do país, das paisagens, das peculiares relações sociais geradas na territorialidade dos fenômenos, na heterogeneidade das culturas.

Por essa consciência, exige-se que estejamos particularmente atentos para a simultaneidade de uma homogeneização cada vez mais crescente entre diferentes lugares do mundo e da diversificação crescente no interior de cada lugar no mundo. Exige-se que estejamos particularmente 
atentos para formas de planejamento territorial que, ao colocar metas de equalização, de uniformidade, pretendendo, sem dúvida, superar disparidades regionais, ao partir de paisagens abstratas, paisagens-receptáculos, paisagens iguais e igualmente desconhecidas, acaba com o ambiente, carregando consigo, na deterioração, a natureza e, mais grave, as formas de compreensão e atuação da sociedade sobre sua própria natureza. As diferenças, as desigualdades, a heterogeneidade, a diversidade, a complementaridade são intrínsecas à compreensão do ambiente, à compreensão da natureza do humano.

Não é o nosso compromisso ver o homem e suas ações como o vilão da história, não é preservar estaticamente o que não é estático. Nosso compromisso está na consciência do papel crescente das atividades humanas na produção de mudanças globais; está na compreensão das contradições, dos conflitos e das pressões; está na compreensão das diferenças, da multiplicidade, da diversidade, com a responsabilidade da complementaridade, da solidariedade. Nosso compromisso está no assumir uma mensagem cultural; ecológica sim, de "uma ecologia mental e social em que os movimentos pelo ambiente, pela ética, tem como sua natureza a solidariedade social e o desenvolvimento individual, a liberdade individual e a responsabilidade social" (GUATTARI, F., As três ecologias).

Espera-se que os espaços possam influir nessas formulações? Como é nossa abordagem para esse geral e esse particular? Como participar para conferir padrões sociais de qualidade de vida, específicos a cada lugar, já que é a cultura de cada lugar que os constitui?

Muitos são os estudos, as pesquisas, os quais deveremos elaborar para cobrir um campo em que estamos bastante a descoberto, para chegar a um projeto compromissado com o ambiente, com a paisagem, com a sociedade. Esse papel de produção do conhecimento para um projeto compromissado responde cabalmente às posturas pessoais em relação à sociedade.

Como enfrentar a compreensão do particular e do geral, em que cada um deles possui suas próprias e complexas formas de elaboração, em um mundo com mudanças extremamente rápidas e crescentes? Não podemos simplesmente partir dos modelos alheios e adaptá-los, ajeitá-los, acochambrá-los para nossas questões.

Como aprimorar nossa acuidade para as diferenças, quando tudo é conduzido para formas cada vez mais crescentes de padronização de pensamentos, de comportamentos, de relacionamentos?

Como compreender o encaixe, a integração das mudanças, que ocorrerão com rapidez e intensidade, devido ao avanço das modernas tecnologias, em um país no qual a mídia, suporte da universalização de movimentos sociais, adota uma reles, uma pífia globalização cultural?

Como montar uma lógica de localização dos espaços de lazer em cidades em que os serviços terão seu papel e seu potencial muito modificados com as mudanças tecnológicas?

Como desenhar os espaços de lazer quando as mudanças tecnológicas agravarão o acúmulo de mão-de-obra ociosa disponível, especialmente nos estratos mais pobres e despreparados?

Como clarificar as mentes em que as classes médias, euforicamente, perseguem o consumismo, apesar de um quadro de pobreza imensa, e contínuo o agravamento da distribuição de renda? Talvez essa seja a única desigualdade aceita com cada vez mais crescente naturalidade ou, pelo menos, com cada vez menos indignação.

Como distinguir "idéias com charme internacional, embora supérfluas, em cidades onde miIhões vivem na pior miséria e violência? Como perceber o que são idéias vendidas como imprescindíveis a nossa modernidade, como atestado de nossa primeira mundice e que, ao invés, nos colocam defendendo causas estúpidas"? (Otávio Frias Filho, Cortina de fumaça, Folha de S. Paulo, set. 1995. 
Qual o perfil de qualificação e educação dos profissionais para que possam distinguir, em seu campo de conhecimento, o que são mudanças adequadas?

Quais os impactos espaciais que a natureza e a abrangência das mudanças tecnológicas irão provocar sobre as culturas locais?

Como contribuir com um desenho urbano que não intensifique a exclusão social?

Como quebrar as pernas de um desenho urbano o qual, ao não privilegiar o espaço público, facilita a manutenção do apartheid social?

Como abrir as mentes de pessoas inteligentes e preparadas tecnicamente, mas que consideram uma praça desqualificada porque abriga mendigos?

Como privilegiar os espaços os quais, a priori, já contam com uma localização a comportar os diferentes horizontes socioculturais?

Como conseguir que instituições públicas e privadas se proponham a novos programas para usos de diferentes públicos? Quais os programas e, especialmente, quais os desenhos, para eventos interativos que intensifiquem, em qualidade e quantidade, as relações de vida coletiva no interno das cidades?

Levando em conta que a violência urbana esvazia espaços extensos e isolados, como obter variedade, plurifuncionalidade, polivalência no conjunto dos diferentes espaços da cidade?

Como viabilizar estudos os quais identifiquem os níveis de preservação, conservação e inovação adequados em cada lugar, vindo a constituir um real patrimônio ambiental urbano?

Teremos condições de ir substituindo nossa prática de projeto, que tem sido preponderantemente para os ricos e especulação imobiliária, para uma prática na qual a estrita articulação entre a ação pública e privada viabilize empreendimentos? Empreendimentos que não só considerem os aspectos técnicos, financeiros, econômicos, mas também se preocupem com a valorização social e estética?

As possibilidades de reformulação das cidades, por renovação de setores urbanos e de lotes urbanos estão, na profissão, com os arquitetos que trabalham com o urbanismo, o planejamento, a edificação. Nós, arquitetos que lidamos com a paisagem, temos problemas muito sérios com a forma de compreensão e atuação da maioria daqueles arquitetos.

Por outro lado, também há lacuna muito séria relacionada aos demais agentes de produção do espaço público, diretamente correlacionados com o nosso projeto (agrônomos, botânicos, geógrafos, viveiristas, executores, etc.) Apesar da especificidade do arquiteto no trato com o projeto, não podemos ser cegos aos demais que, de uma forma ou de outra, queiramos ou não, têm a possibilidade de intervir no espaço. Não temos sido capazes de lidar corretamente com a participação das outras formações. Não temos sido capazes de transformar nossas precárias associações em instituições as quais, pela excelência de seu caráter científico, angariassem os créditos para aceitar, qualificar e conferir os papéis e dimensões adequadas a todas as diferentes contribuições.

Às mudanças com que, no país, de uma forma ou de outra, deveremos necessariamente nos deparar, cabe um lugar de destaque à pesquisa e aos núcleos de caráter científico; a elas caberá o avanço em um estágio muito mais complexo de produção do conhecimento; elas serão um fórum privilegiado para promover o debate e a difusão do trabalho coletivo, agregado em diversas Instituições e formações. Deveremos nos propor passos mais largos, de maior fôlego, em nossas pesquisas, em nossas reuniões, em nossa vontade de criar estímulos para atividades coletivas intermediárias de troca, de difusão, utilizando formas alternativas de comunicação. 
Pretendi dar início, neste ENCONTRO, à valorização do avanço da pesquisa em nossas instituições docentes, públicas ou privadas e à troca viva, efusiva, tolerante e generosa do que sabemos e do que desconhecemos.

Obs.: Texto originalmente publicado nos Anais do II ENEPEA - Encontro Nacional de Ensino de Paisagismo em Escolas de Arquitetura e Urbanismo do Brasil, Universidade São Marcos/FAUUSP. 